\title{
Acute abdomen due to torsion of the wandering spleen in a patient with Marfan Syndrome
}

\author{
Laura Leci-Tahiri, Afrim Tahiri', Rifat Bajrami and Mehmet Maxhuni
}

\begin{abstract}
Wandering spleen is a very rare defect characterized by the absence or weakness of one or more of the ligaments that hold the spleen in its normal position in the upper left abdomen. Patient symptomatology is variable and ranges from mere feeling of an abdominal lump to sudden abdominal pain due to infarction. Patients may have subacute to chronic abdominal or gastrointestinal complaints. Because of nonspecific symptoms, clinical diagnosis can be difficult; hence, imaging plays an important role. A major complication is splenic torsion, which is the cause of acute abdomen. We present a case of acute abdominal pain due to torsion of wandering spleen in a patient with Marfan Syndrome, valvular heart disease, and vertebral anomalies. Preoperative diagnosis was made on the basis of ultrasonography and computed tomography, which was later confirmed on surgery, and treated successfully.
\end{abstract}

\section{Case presentation}

A 36-year-old Albanian man presented to Emergency Unit with complaints of abdominal pain, two-week history of constipation, and a tumor in the right lower abdomen (Figure 1).

The patient presented with features of Marfan syndrome: increased height, arachnodactyly, long limbs, contractures of the hand, pectus excavatum, genu recurvatum, and scoliosis. He had undergone mitral valve implantation 15 years previously, and had been treated with oral anticoagulants.

At admission, the patient was afebrile, pale, rundown, and fully conscious. His left lower extremity was oedematous under the knee. Abdomen was soft on palpation with a $20 \times 9 \mathrm{~cm}$ mass palpable in the right hypogastric region.

Doppler examination of the lower extremity veins showed thrombosis of the left popliteal and left tibialis posterior vein. A vascular surgeon was consulted, and heparin with a high molecular weight, 7500 UI, was administered every 6 hours intravenously.

Due to lung problems, a pulmonologist was further consulted, who found pleuropneumonia in the left lung. The patient suffered from arterial hypertension and chronic cardiomyopathy.

\footnotetext{
* Correspondence: dr.afrimi@hotmail.com

Clinic of Surgery, University Clinical Center of Kosova, Prishtina, Kosova
}

Laboratory investigations showed mild anaemia and leucocytosis. Tumor markers were checked but were all within normal limits.

\section{Ultrasound of the abdomen}

Absence of the spleen in its normal position in the left hypochondrium, and presence of tumor mass in the right fossa inguinalis. Other organs of the abdomen were normal.

\section{Magnetic resonance imaging of the abdomen and pelvis} Absence of the spleen in the normal location. The spleen was seen in the lower right hemiabdomen, enlarged, with the size of $18.7 \times 8.5 \times 20.8 \mathrm{~mm}$ and sacral meningocoele.

\section{CT angiography of abdominal vessels}

Splenic artery was divided by pancreatic artery, which was forwarded to the tail of pancreas giving it a "whorled appearance", and from this level splenic vessels were thrombosed. Pancreas was moved forward without obvious radiological changes (Figures 2 and 3 ).

Operative findings revealed a huge spleen in the pelvic area with torsion of the vascular pedicle starting at the tail of the pancreas (Figure 4). The characteristic "whirl sign" can be seen in the area of the splenic vascular pedicle, indicative of torsion (Figure 5). Other internal organs were normal. 


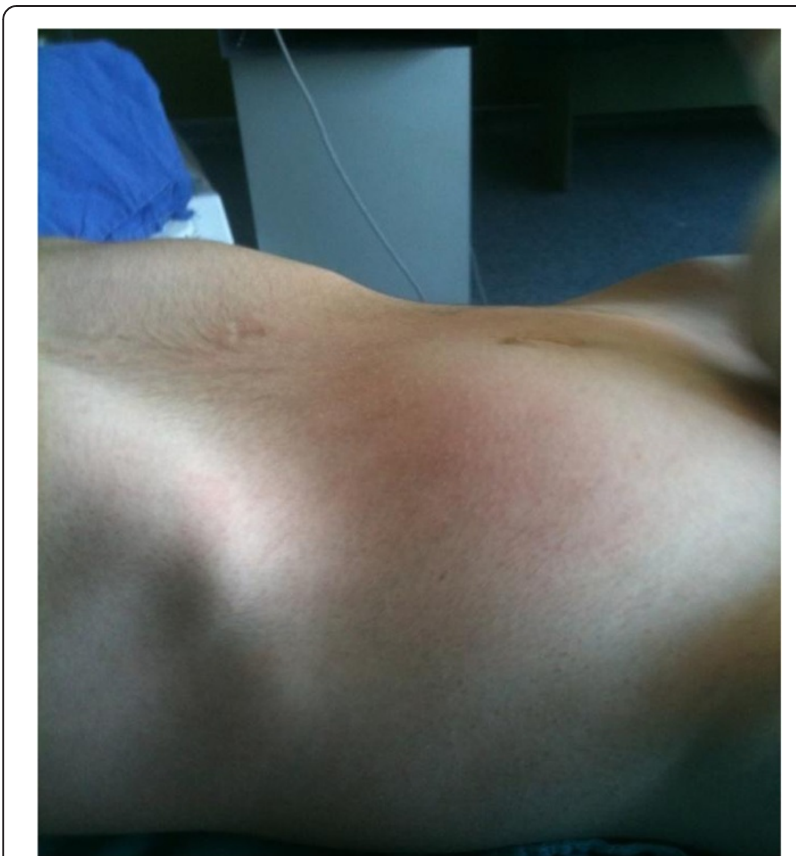

Figure 1 Tumor in the right lower abdomen.

A total splenectomy was performed, as the organ appeared congested, it was likely infarcted and not likely to be salvageable (Figure 6).

The patient recovered well after the operation. Antibiotics, analgesics, plasma, blood, low molecular weight heparin, vitamins and triple vaccination (against pneumococcus, hemophilus influenza, and meningococcus) were given.

He was discharged on oral anticoagulants because of heart disease.

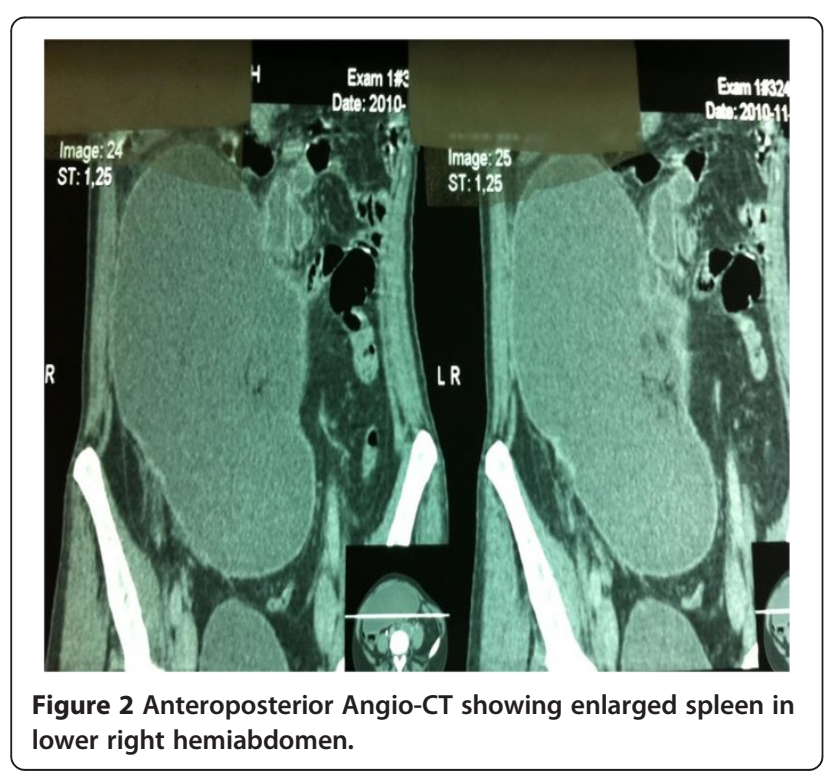

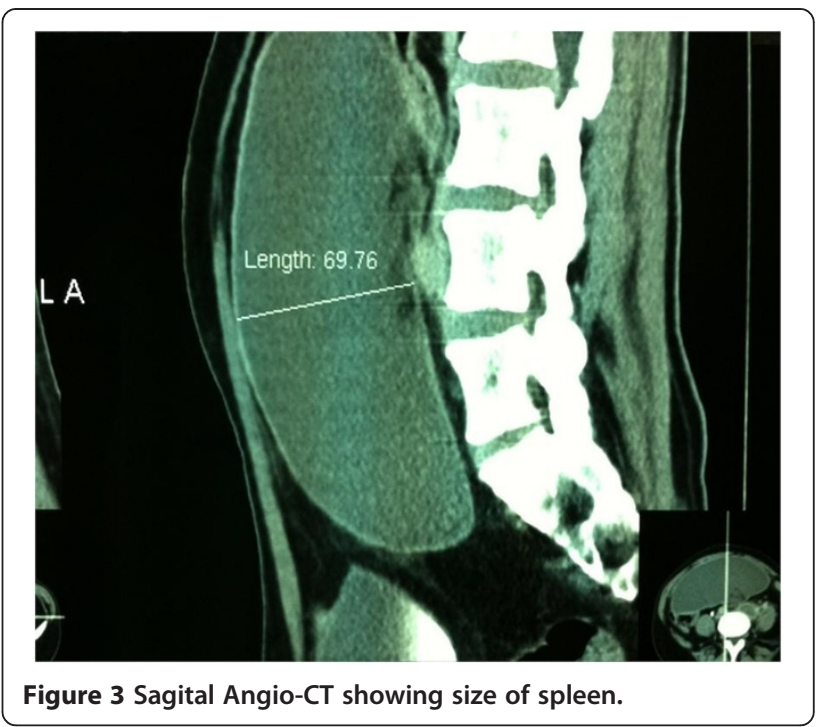

Histology revealed acute thrombotic changes in arteries and veins of the splenic hilum, with diffuse hemorrhagic and ischaemic infarcts of the spleen.

\section{Discussion}

Wandering spleen is an uncommon clinical entity, which rarely affects children and adolescents. Discussion in the literature has been limited to case reports and small case series [1]. The condition is not hereditary.

Congenital wandering spleen is a very rare randomly distributed birth defect characterized by the absence or weakness of one or more of the ligaments that hold the spleen in its normal position in the upper left abdomen. Instead of ligaments, the spleen is attached by a stalklike tissue supplied with blood vessels (vascular pedicle). If the pedicle is twisted in the course of the movement of the spleen, the blood supply may be interrupted or

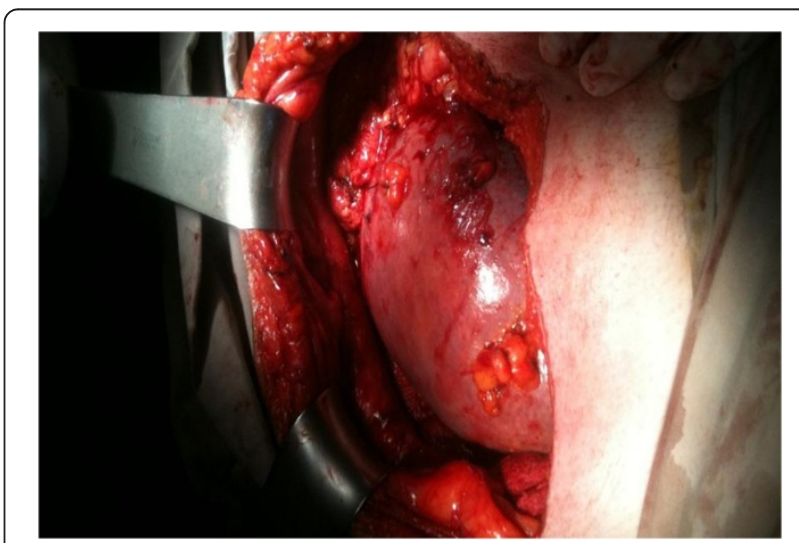

Figure 4 Huge spleen in right pelvic area. 


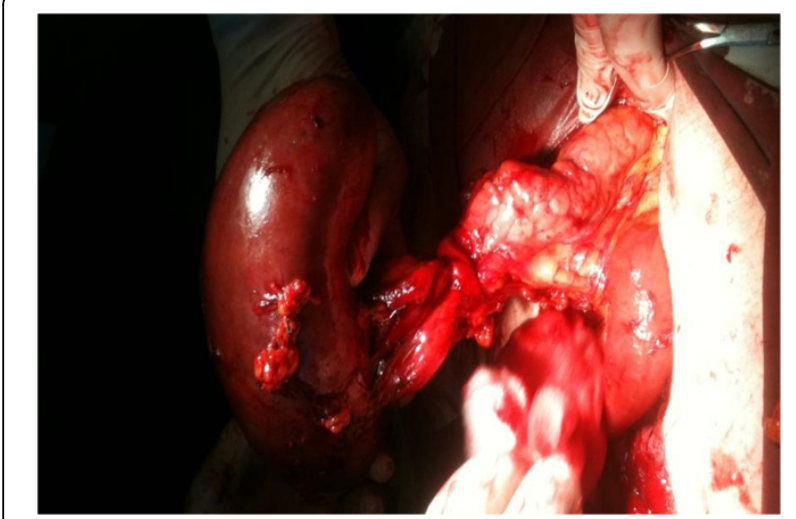

Figure 5 "Whirl sign" in the area of the splenic vascular pedicle, indicative of torsion.

blocked (ischaemia) to the point of severe damage to the blood vessels (infarction). Because there is little or nothing to hold it in place, the spleen "wanders" in the lower abdomen or pelvis where it may be mistaken for an unidentified abdominal mass.

"Acquired" wandering spleen may occur during adulthood due to injuries or other underlying conditions that may weaken the ligaments that hold the spleen in its normal position (connective tissue disease or multiparity) $[2,3]$.

Van Horne, a Dutch physician, is credited with describing this condition in 1667 after performing an autopsy. In 1875, Martin, a German obstetrician, performed the first splenectomy for a wandering spleen $[4,5]$. Ten years later, splenopexy was described and considered superior to splenectomy, a differential preference that has changed several times over the years. Since Van Horne's discovery, approximately 400 cases of wandering spleen have been reported worldwide. It is a rare entity accounting for less than $0.25 \%$ of splenectomies

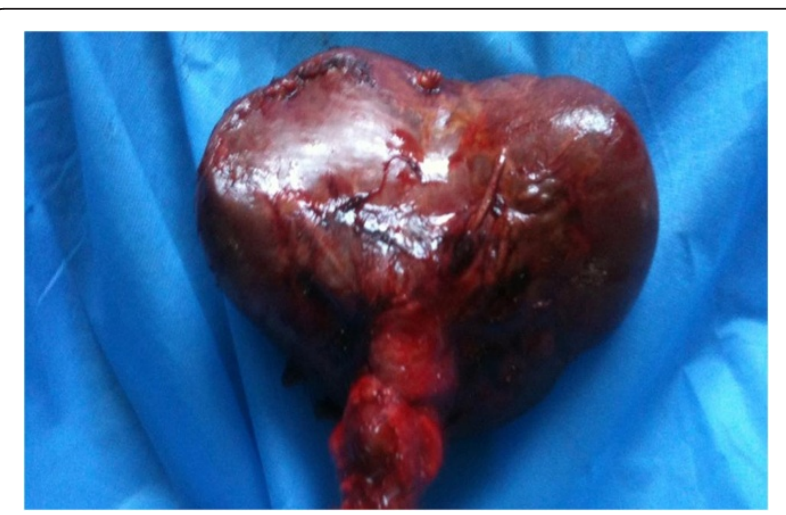

Figure 6 Spleen with diffuse hemorrhagic and ischemic infarcts.
[6]. Twenty one cases of wandering spleen, including our present case, have been reported in the English literature during the past decade (Table 1). The majority of patients are female, in second and third decade of life. Computed tomography is the imaging method of choice for diagnosing wandering spleen. The usual location of wandering spleen is pelvis and left iliac fossae. We couldn't find in literature the location in right iliac fossa, as our case showed. Abdominal pain, intestinal obstruction, nausea, vomiting, fever, and a lump in the abdomen or the pelvis are the common symptoms in all reported cases. Splenectomy is performed in most cases.

Discussion in the literature is limited, especially in cases with Marfan Syndrome and valvular heart disease. We have found only one case with wandering spleen in a child with Marfan Syndrome [7].

Marfan syndrome is caused by a defect, or mutation, in the gene that determines the structure of fibrillin-1, a protein that is an important part of connective tissue. It is an inherited disorder of the connective tissue that affects major organ systems of the body: the heart and circulatory system, thebones and muscles, and the eyes. A person with Marfan syndrome is born with the disorder, even though it may not be diagnosed until later in life [7].

As it is a generalized connective tissue disorder, congenital laxity of the primary ligamentous attachments of the spleen might predispose to splenic hypermobility and hence torsion in childhood, in contrast to the more common acquired form of splenic torsion seen in multiparous females that is believed to be caused by laxity of these ligaments owing to hormonal changes and multiparity [7-9].

Symptoms of wandering spleen are those typically associated with an abnormal size of the spleen (splenomegaly) or the unusual position of the spleen in the abdomen $[9,10]$.

Patients maybe asymptomatic or may present with acute abdominal pain. The common clinical presentation is abdominal mass with pain. It may occur in people of all ages with a predilection for male under 10 years of age and for female patients in older age groups, being most common in multiparous women. Under the age of 10 the sex distribution is even, whereas over 10 years of age, females out number males by seven to one. A study involving 66 children under 10 years showed that $50 \%$ of wandering spleens were lost through acute ischaemia $[7,9,11]$.

Splenic torsion is usually clockwise. Complications of splenic torsion include: gangrene, abscess formation, local peritonitis, intestinal obstruction and necrosis of the pancreatic tail, which can lead to recurrent acute pancreatitis $[6,12,13]$. 
Table 1 The characteristics of the reported cases of wandering spleen

\begin{tabular}{|c|c|c|c|c|c|c|}
\hline Case & Age & Gender & Diagnostic modality & Spleen location & Type of surgery performed & Reference \\
\hline 1 & 26 & $\mathrm{~F}$ & $\mathrm{CT}$ & Hypogastric region & Splenectomy & Pan Afr Med J 2012 \\
\hline 2 & 27 & $\mathrm{~F}$ & US, CT & Left lower quadrant & Splenopexy & Saudi J Gastroenterol 2010 \\
\hline 3 & 28 & $\mathrm{~F}$ & $\mathrm{CT}$ & Left lower quadrant & Splenopexy & Case Rep Surg 2013 \\
\hline 4 & 44 & M & CT & Lower pelvis & Splenectomy & N Am J Med Sci 2011 \\
\hline 5 & 20 & $\mathrm{~F}$ & CT & Right upper quadrant & Splenopexy & JSLS 2008 \\
\hline 6 & 19 & $\mathrm{~F}$ & Doppler, Gl endoscopy & Left iliac fossa & Splenopexy & JSLS 2007 \\
\hline 7 & 41 & $\mathrm{~F}$ & $\mathrm{CT}$ & Left lower quadrant & Splenectomy & JSLS 2012 \\
\hline 8 & 21 & $\mathrm{~F}$ & $\mathrm{CT}$ & Intrathoracal & Splenopexy & J Blood Med 2011 \\
\hline 9 & 9 & $\mathrm{~F}$ & CT & Periumbilical & Splenectomy & Br J Radiol 2010 \\
\hline 10 & 15 & M & $\mathrm{CT}$ & Left iliac fossa & Splenectomy & Cases J 2008 \\
\hline 11 & 64 & M & $\mathrm{CT}$ & Left hemothorax & Splenectomy & BMC Gastroenterol 2006 \\
\hline 12 & 28 & $\mathrm{~F}$ & $\mathrm{CT}$ & Pelvis & Splenectomy & Am J Surg 2008 \\
\hline 13 & 21 & $\mathrm{~F}$ & US, CT & Pelvis & Splenectomy & Hong Kong Med J 2012 \\
\hline 14 & 9 & $\mathrm{~F}$ & $\mathrm{CT}$ & Pelvis & Splenectomy & PediatrEmerg Care 2003 \\
\hline 15 & 4 & $\mathrm{~F}$ & US, CT & Left lower quadrant & Splenectomy & ActaRadiol 2011 \\
\hline 16 & 4 & $\mathrm{~F}$ & $\mathrm{CT}$ & Left hemothorax & Splenopexy & AJR 2012 \\
\hline 17 & 28 & $\mathrm{~F}$ & US,CT & Right upper quadrant & Splenectomy & Singapore Med J 2007 \\
\hline 18 & 30 & $\mathrm{~F}$ & CT & Left lower quadrant & Splenectomy & BratisILekListy 2009 \\
\hline 19 & 19 & $\mathrm{~F}$ & $\mathrm{CT}$ & Pelvis & Splenectomy & Bratis|LekListy 2009 \\
\hline 20 & 16 & $\mathrm{~F}$ & US & Pelvis & Splenopexy & SA FamPract 2010 \\
\hline 21 & 36 & M & $\mathrm{CT}$ & Right iliac fossa & Splenectomy & Present study \\
\hline
\end{tabular}

Splenopexy is the treatment of choice for a noninfarcted wandering spleen. One small case study in 2004 demonstrated successful laparoscopic splenopexy using a Vicryl mesh bag. Splenic preservation in cases of wandering spleen without rupture or infarction avoids the risk of overwhelming postsplenectomy sepsis, and a laparoscopic approach allows for shorter hospital length-of-stay and decreased postoperative pain $[12,14,15]$.

Splenectomy should be done only when there is no evidence of splenic blood flow after detorsion of the spleen. In our patient, because of the intraoperative findings of splenic infarction, splenectomy was performed $[12,16]$.

\section{Conclusion}

The possible diagnosis of wandering spleen should be kept in mind when $\mathrm{CT}$ shows the spleen to be absent from its usual position and a mass is found elsewhere in the abdomen or pelvis. Abdominal ultrasonography (with or without Doppler) and CT are useful investigative tools. Early intervention is necessary to reduce the risk of splenic infarction and other complications. An awareness of the condition together with the use of appropriate medical imaging can lead to the correct diagnosis.

\section{Consent}

Written informed consent was obtained from the patient for publication of this case report and any accompanying images. A copy of the written consent is available for review by the Editor-in-Chief of this journal.

\section{Competing interests}

The authors declare that they have no competing interests.

\section{Authors' contributions}

AT and RB performed the surgery, supervised the patient's care, drafted the manuscript, and approved the version submitted for publication. LT and MM assisted with patient care and have been involved in drafting the manuscript. AT, LT and MM has been involved in drafting and revising the manuscript. All authors read and approved the final manuscript.

Received: 1 February 2013 Accepted: 23 July 2013

Published: 5 August 2013

\section{References}

1. Brown CV, Virgilio GR, Vazquez WD: Wandering spleen and its complications in children: a case series and review of the literature. J Pediatr Surg 2003, 38:1676-1679.

2. March of Dimes Birth Defects. Internet: htpp://www.marchofdimes.com.

3. Genetic and Rare Diseases. Internet: htpp://rarediseases.info.nih.gov.

4. Dahiva N, Karthikeyan D, Vijav S, Kumar T, Vaid M: Wandering spleen: Unusual presentation and course of events. Abdom Imaging 2002, 12:359-362

5. Tan HH, Ooi LLPJ, Tan D, Tan CK: Recurrent abdominal pain in awoman with a wandering spleen. Singapore Med J Case Report 2007, 48:122-124. 
6. Khoi L, Devan G, William WH, Darryl T: Splenic Torsion Requiring Splenectomy Six Years Following Laparoscopic Nissen Fundoplication. JSLS 2012, 16:184-188.

7. Sodhi KS, Gupta P, Rao KLN, Marwaha RK, Khandelwal N: Marfanoid hypermobility syndrome and skeletal abnormalities in a rare case of torsion of wandering spleen. BJR 2008, 81:145-148.

8. Huai-Tzu ML, Kenneth KL: Wandering Spleen: An Unusual Association with Gastric Volvulus. AJR 2007, 188:328-330.

9. Desai DC, Hebra A, Davidoff AM, Schnaufer L: Wandering spleen: a challenging diagnosis. South Med J 1997, 90:439-443.

10. Befikadu S, Gudu W, Abseno N: Torsion of a pelvic wandering spleen as a cause of acute abdomen in a woman: a case report and review of the literature. Ethiop Med J 2004, 42:53-61.

11. Fujiwara T, Takehara Y, Isoda H, Ichijo K, Tooyama N, Kodaira N, Kitanaka H, Asai T, Kawaguchi K: Torsion of the wandering spleen: $\mathrm{CT}$ and angiographic appearance. J Comput Assist Tomogr 1995, 19:84-86.

12. Dawson JH, Roberts NG: Management of the wandering spleen. Aust NZJ Surg 1994, 64:441-444.

13. Romero JR, Barksdale EM Jr: Wandering spleen: a rare cause of abdominal pain. Pediatr Emerg Care 2003, 19:412-414.

14. Khurana B: The Whirl Sign. Radiology 2003, 226:69-70.

15. Ben Ely A, Zissin R, Copel L, Vasserman M, Hertz M, Gottlieb P, Gayer G The wandering spleen: $\mathrm{CT}$ findings and possible pitfalls in diagnosis. Clin Radiol 2006, 61:954-958.

16. Bakir B, et al: Acute torsion of a wandering spleen: imaging findings. Abdom Imaging 2004, 29:707-709.

doi:10.1186/1749-7922-8-30

Cite this article as: Leci-Tahiri et al: Acute abdomen due to torsion of the wandering spleen in a patient with Marfan Syndrome. World Journal of Emergency Surgery 2013 8:30.

\section{Submit your next manuscript to BioMed Central and take full advantage of:}

- Convenient online submission

- Thorough peer review

- No space constraints or color figure charges

- Immediate publication on acceptance

- Inclusion in PubMed, CAS, Scopus and Google Scholar

- Research which is freely available for redistribution 